\title{
Plataforma de baixo custo como alternativa para o Cubetto
}

\author{
Prabhát K. de Oliveira ${ }^{1}$, Felipe Cardoso $^{1}$, Marcos R. Sousa ${ }^{1}$, Martha X. T. Delgado ${ }^{1}$ \\ ${ }^{1}$ Ciência da Computação - Departamento de Ciências Exatas e Tecnológicas \\ Universidade Estadual de Santa Cruz (UESC) \\ 45.662-900 - Ilhéus - BA - Brasil \\ bartkoliveira@gmail.com, felipecardoso5@hotmail.com, mrpsousa@outlook.com, \\ mxtdeuesc.br
}

\begin{abstract}
This article presents the construction of a low-cost prototype of the Cubetto toy and the development of some experiments for introduction to programming logic. Cubetto is a simple educational robotics platform that aims to teach programming logic to children between 4 and 8 years old. The prototype presented consists of a motorized car, in addition to a control interface based on the concept of analog keyboards, both the car and the control interface use Arduino UNO and Bluetooth protocol for communication. The materials used in the construction of this prototype were chosen under the premise of economy, its correct operation has been proven in addition to having a average price of $78 \%$ cheaper than the original.
\end{abstract}

Resumo. Este artigo apresenta a construção de um protótipo de baixo custo do brinquedo Cubetto e a elaboração de alguns experimentos para introdução na lógica de programação. O Cubetto é uma plataforma de robótica educacional simples que visa ensinar lógica de programação para crianças entre $4 e$ 8 anos. O protótipo apresentado consiste de um carro motorizado, além de uma interface de controle baseada no conceito de teclados analógicos, tanto o carro quanto a interface de controle utilizam Arduino UNO e protocolo Bluetooth para comunicação. Os materiais utilizados foram escolhidos sob a premissa de economia, foi comprovado o seu correto funcionamento além de possuir um preço médio de $78 \%$ mais barato que o original.

\section{Introdução}

A robótica educacional é uma estratégia de aprendizagem que consiste na criação e exploração de ambientes interativos onde os alunos podem montar, programar e analisar o comportamento de um robô ou sistema robotizado. Estes ambientes promovem a socialização e a autonomia no aprendizado, criando um cenário multidisciplinar capaz de envolver conceitos de mecânica, eletrônica e computação além de permitir explorar outros temas como matemáticas, ciências, línguas, ciências sociais, entre outros. A robótica educacional permite aos educadores apresentar de forma lúdica e atrativa conceitos teóricos ou de difícil compreensão [Fernandes 2013, dos Santos et al. 2013, Torcato 2012, Cambruzzi 2014, Benitti et al. 2009, Pereira and Costa 2010, Zilli 2004, Rodarte 2014].

O brinquedo Cubetto [Cubetto 2013] é uma plataforma de robótica educacional simples que visa ensinar lógica de programação para crianças entre 4 e 8 anos, foi projetado pela empresa Primo em Londres e vende o produto em vários países inclusive no 
Brasil, onde o preço é relativamente alto, $\mathrm{R} \$ 1.910,00$ em 2020; em Alemanha é vendido por \$ 218,00 euros e em Canadá é vendido por \$ 305,00 dólares canadenses.

O Cubetto consiste num robô que realiza movimentos através da disposição de blocos em uma interface de controle, podendo ser utilizado em conjunto com um tabuleiro educativo para movimentar o robô, que através de "programação" resolve diferentes desafios, o robô dispensa o uso de computador, tablet ou celular.

Este artigo descreve os procedimentos da construção de um protótipo baseado no brinquedo Cubetto utilizando materiais e componentes de baixo custo, tanto na interface de controle quanto no robô utiliza-se uma placa microcontroladora Arduino UNO para fazer a gerência dos componentes. Além disso apresentam-se exemplos de atividades pedagógicas com o objetivo de introduzir às crianças aos conceitos básicos de programação, incluindo o conceito de função.

Na seção 2 serão apresentados os trabalhos correlatos comparando-os com a nossa proposta. Na seção 3, será abordada a metodologia utilizada. Na seção 4, apresenta-se o desenvolvimento, onde é descrito cada parte que compõe o projeto: o veículo, a interface de controle, os blocos de codificação, o tabuleiro educativo e o processo de comunicação. Na seção 5, são apresentados os resultados. Na seção 6 e na seção 7 são descritas as conclusões e os trabalhos futuros respetivamente.

\section{Trabalhos Correlatos}

O Cubetto foi projetado por Filippo Yacob, Ben Callicott e Matteo Loglio, foi financiado via Kickstarter e tem ganhado vários prêmios a nível mundial. A principal inspiração do Cubetto foi o ambiente LOGO tradicional, desenvolvido em meados dos anos 60 pelo professor Seymour Papert no MIT. A principal caraterística da linguagem LOGO é sua flexibilidade para poder ser utilizada tanto por crianças quanto por adultos experientes, apresenta comandos simples e intuitivos, além disso é acompanhada de uma parte gráfica [de Souza et al. , BATISTA, Azevedo et al. 2010]. No ambiente gráfico tem-se uma tartaruga que faz o papel de robô virtual, que se movimenta no espaço da tela através de comandos executados pelo usuário, exemplos de comandos são: para frente, para trás, para direita e para esquerda. Este tipo de ambientes possibilita o ensino de noções de programação junto com o treino de formas e figuras geométricas, letras e números. Também tem sido usado no ensino fundamental na realização de operações aritméticas e à associação de cores. Além de ter sido utilizado para proporcionar noções de direção, localização e distância [Azevedo et al. 2010].

O Cubetto consiste de uma interface de controle com um botão de início (botão start) e blocos de madeira que são encaixados nele além de um robô motorizado (veículo) que se conecta à interface de controle através de comunicação sem fio. Os blocos de madeira representam as instruções: frente, esquerda, direita e função, são de diferentes cores e sua forma é associada com a ação que realizam. È suficiente encaixar os blocos de madeira em sequência para criar um código e pressionar o botão presente na interface de controle para que o veículo comece a se mover seguindo as instruções.

No Cubetto, o veículo é a tartaruga do ambiente LOGO e os blocos de madeira substituem a linguagem de texto usada no LOGO [Abelson 1974]. Portanto, este brinquedo aborda de forma simples os conceitos básicos de programação de modo que até 
mesmo uma criança que não sabe ler e escrever pode fazer uso dele, tornando os comandos de programação algo que se pode tocar. Importante salientar que o Cubetto inclui uma instrução chamada function, e além disso inclui uma área no interface de controle chamada de function line. Nesta área pode-se armazenar uma sequência de instruções específica, esta sequência será executada cada vez que seja encaixado o bloco de madeira correspondente à instrução function. Portanto, o Cubetto apesar de ter uma interface simples adiciona conceitos complexos de lógica de programação. Portanto, sua principal vantagem é sua simplicidade em contraposição com o preço elevado de $\mathrm{R} \$ 1.910,00 \mathrm{em}$ 2020, preço de venda por unidade pela empresa comercializadora.

O kit Buddy Berry [Kaviatkovski et al. 2016], construído na Universidade Técnológica Federal de Paraná é também inspirado no Cubetto. Foi utilizado o Arduino Mega 2560 para desenvolver a interface de controle, utilizam o protocolo Zigbee para a comunicação sem fio além de utilizar motores DC e controlador PID para a implementação do robô motorizado e também desenvolveram suas próprias peças com estrutura semelhante ao Cubetto. O custo total para o desenvolvimento do kit Buddy Berry ficou no valor de $\mathrm{R} \$ 1.399,00 \mathrm{em} 2016$, levando em conta apenas o valor dos materiais utilizados na construção, se for incluso o custo da mão de obra, pode-se considerar um valor mais próximo do Cubetto, tornando o kit Buddy Berry, uma opção de custo elevado.

O projeto [da Silva and da Cruz Fagundes 2016], também segue a mesma linha do desenvolvimento de kit robótico de baixo custo, desenvolvido pela Comunidade Jabuti Edu, o projeto de Robótica Educacional Livre Jabuti tem como objetivo principal desenvolver uma plataforma simples e com custos acessíveis para que crianças e adolescentes possam aprender robótica. Sua construção baseia-se no microcomputador Raspberry Pi, e incorpora o uso de tecnologias livres, juntamente com um par motores, LEDs e um sistema Linux. O kit Jabuti não possui interface de controle, a interação das crianças é feita através de um computador que fornece uma interface amigável com comandos simples, a vantagem principal é que é livre portanto disponível para reprodução a desvantagem é a necessidade de computador e também o custo do robô móvel que baseia-se na placa Rabsberry Pi que possui em média um valor 3 vezes maior que uma placa Arduino UNO.

O protótipo aqui proposto é uma opção de baixo custo pois as peças utilizadas para a confecção da interface de controle, os blocos de comandos e o tabuleiro didático foram escolhidas com este intuito além de utilizar Arduino UNO tanto na interface de controle quanto no robô móvel e usar o protocolo de comunicação Bluetooth. Tudo isto fez com que ficasse com um preço muito menor que todos os anteriores.

\section{Metodologia}

A metodologia foi dividida em diferentes fases, a primeira constitui-se em realizar um estudo de referência acerca das tecnologias utilizadas para o desenvolvimento do projeto Cubetto. A fase seguinte consistiu na seleção de elementos baixo custo para compor a estrutura dos protótipos. A terceira fase consistiu na aquisição dos materiais eletrônicos, como Arduinos, módulo bluetooth e motores, para o desenvolvimento dos protótipos do veículo e da interface de controle. A quarta foi a etapa de avaliação dos protótipos, onde foram realizados os testes de funcionamento e conexão das interfaces desenvolvidas e movimentação e resposta aos comandos do veículo. Na quinta fase, foi a construção 
de um tabuleiro educativo e elaboração de exemplos de execução para o aprendizado de programação.

\section{Desenvolvimento}

No nosso protótipo a interface de controle foi construída de forma visualmente semelhante à interface do kit Cubetto original, assim como quantidade de slots de peças, LEDs indicadores, botão de iniciar movimento e seção reservada para blocos de função. De maneira geral, o protótipo produzido é composto por quatro partes físicas; uma interface de controle, um veículo motorizado, um tabuleiro educativo, simulando o local de trânsito do veículo e Blocos de Codificação que se encaixam à interface. A comunicação entre a interface de controle e o veículo é feita com o uso de módulos bluetooth HC-05.

\subsection{Veículo}

O primeiro passo para a realização do projeto foi a construção do veículo que pudesse executar movimentos básicos como mover à frente e girar em $90^{\circ}$ para esquerda ou direita (figura 1).

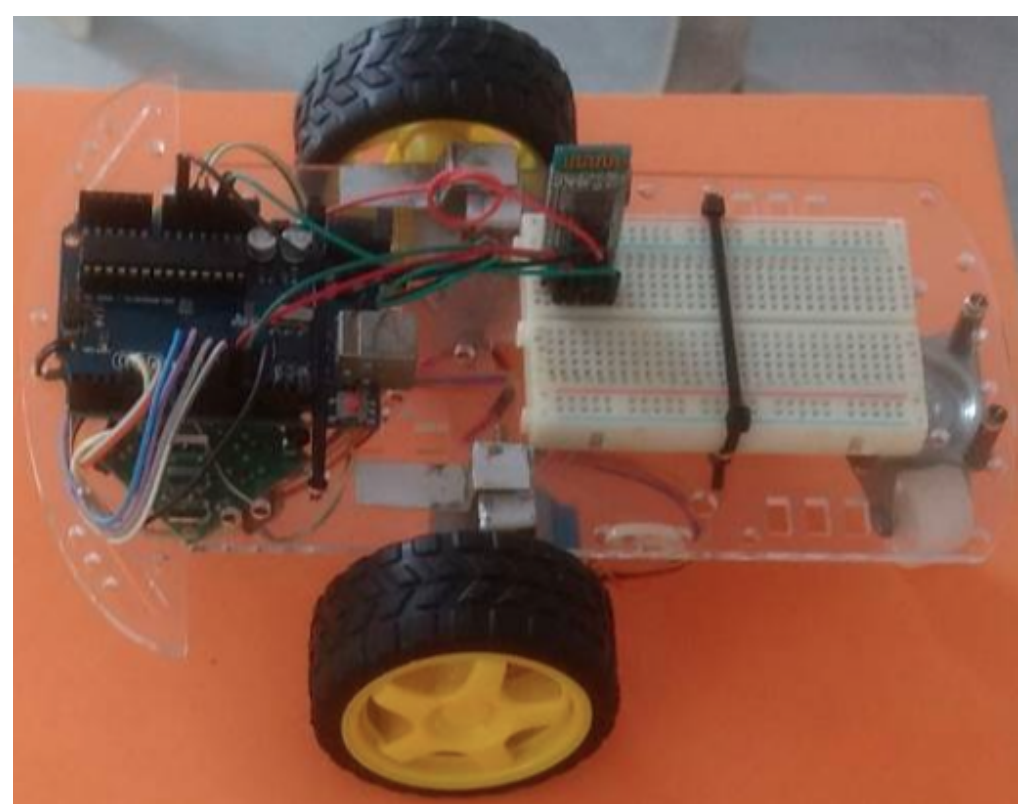

Figure 1. Protótipo do carrinho com o módulo bluetooth, motores e bateria acoplados

Depois de explorar vária alternativas para usar como robô motorizado foi selecionado o kit chassi de acrílico do tipo 2WD, contendo 2 motores DC, 2 rodas de borracha, 1 chassi em acrílico e 1 roda boba universal, a escolha foi baseada no baixo custo do mesmo. Nele foi montada a placa Arduíno UNO, um módulo bluetooth HC-05 e uma bateria de $9 \mathrm{~V}$. O microcontrolador faz o controle dos motores e o recebimento das informações através do HC-05. O robô recebe o comando de andar para frente e então ele vai se deslocar em linha reta uma determinada distancia fixa. Também vai receber o comando virar para direita e vai ter que fazer um giro de 90 graus para direita e quando receber o comando virar para esquerda vai fazer um giro de 90 graus para esquerda. Para este objetivo preferiu-se utilizar 2 motores de passo, modelo 28BYJ-48 custando em 
média $\mathrm{R} \$ 19,00$, em lugar dos motores DC próprios do chassi. O principal motivo foi a imprecisão dos movimentos pois, sendo que para melhorá-los seria necessário o uso de sensor fotoelétrico e a implementação de controlador PID. Já o motor de passo tem como vantagem a facilidade de implementação e melhor precisão em circuito aberto pois deslocam um ângulo de $1,8^{\circ}$ a cada pulso recebido do drive de controle.

\subsection{Interface de controle e blocos de codificação}

A interface de controle do Cubetto original possui 16 slots, então o protótipo da interface foi desenvolvido com este objetivo. Ela possui 16 encaixes, 12 de linha de comando e quatro para função, um botão switch (botão start) para acionar o envio dos comandos ao robô e 16 LEDs indicadores, como mostrado na Figura 2.

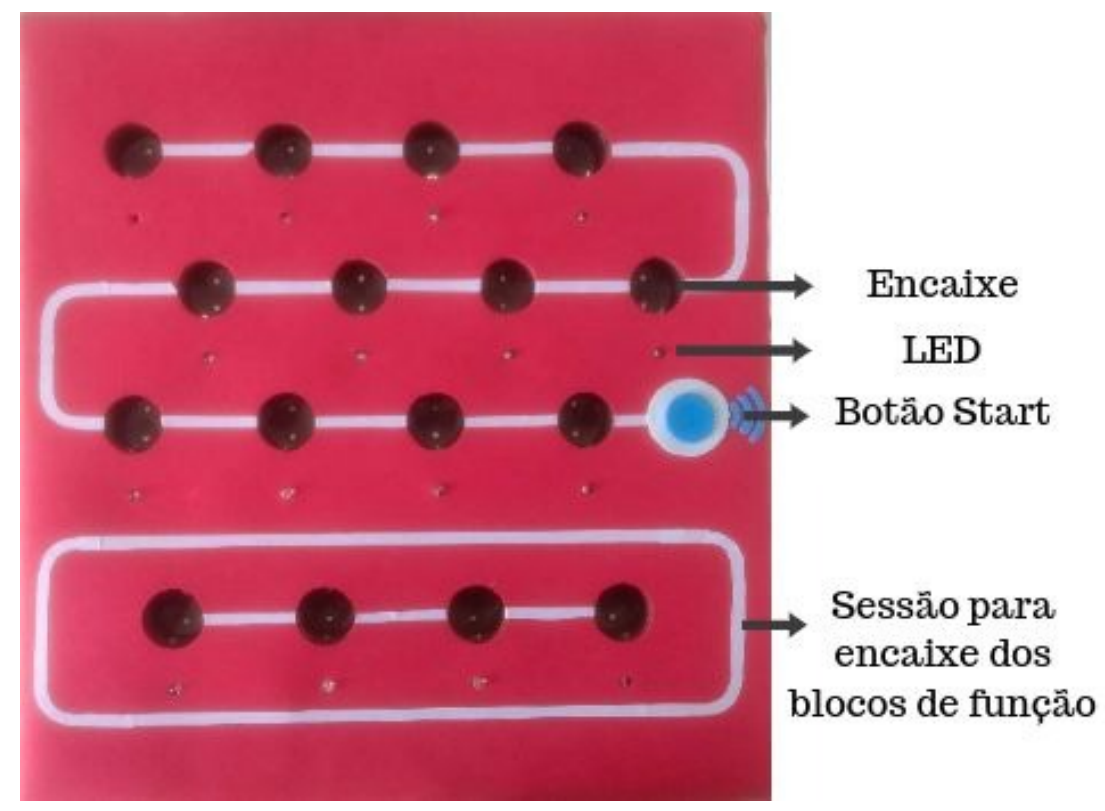

Figure 2. Interface de controle com encaixes para botões e leds indicadores

A estrutura da interface de controle foi projetada para ser de baixo custo e utilizar materiais mais acessíveis. Após alguns testes com diversos materiais, constatou-se que o melhor material para a construção da estrutura interna da interface foi o compensado de madeira $50 \mathrm{~cm} \times 60 \mathrm{~cm}$ com $4 \mathrm{~mm}$ de espessura, adquirido por $\mathrm{R} \$ 20,00$, pois apresentou a melhor relação custo $\mathrm{x}$ benefício e maior robustez a interface o que é um fator fundamental, uma vez que o painel será manuseado por crianças e precisa apresentar resistência e durabilidade. Um revestimento com emborrachado colorido foi feito em torno da plataforma, para torná-la mais amigável e para isso foi utilizado a borracha EVA, que ao mesmo tempo protege o compensado da umidade, adquirido por $\mathrm{R} \$ 2,50$ unidade $\mathrm{e}$ foram usadas 3 no total na confecção da interface, pois apresenta características relevantes como ser atóxico, aderente e resistente.

Os blocos de decodificação, mostrados na figura 3, substituem os blocos de madeira mencionados acima do Cubetto original, também foram reproduzidos em borracha de EVA e se conectam na interface de controle através dos encaixes, por meio de um par de imãs de neodímio, de maneira similar à descrita em [Kaviatkovski et al. 2016]. 


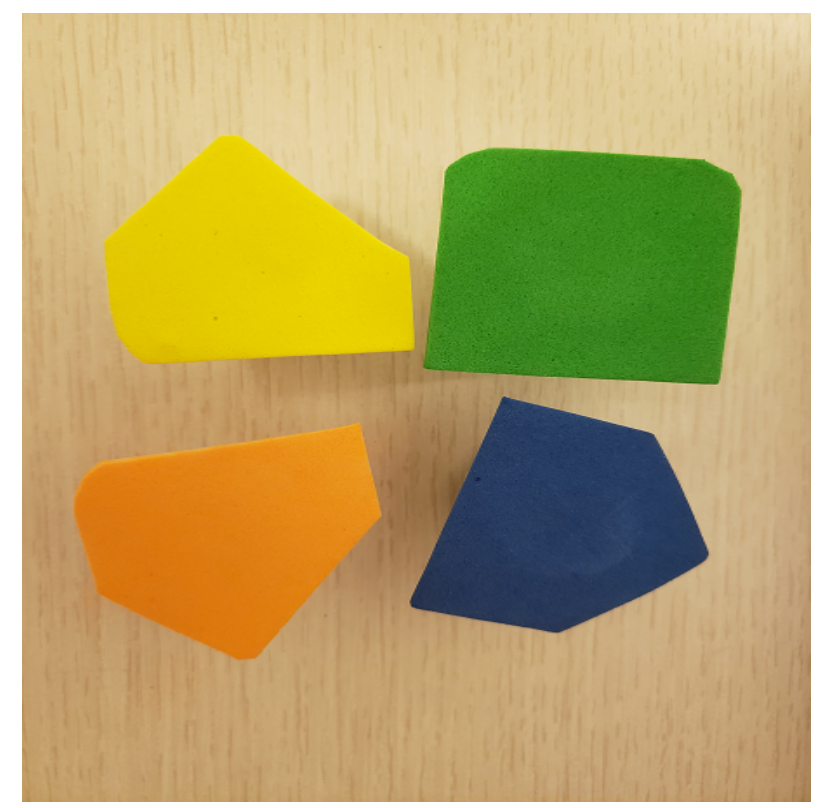

Figure 3. Blocos de codificação

O objetivo dos blocos é oferecer uma linguagem de programação tangível, facilitando a introdução de dados na interface, neste sentido foram elaborados 4 tipos de blocos onde cada um representa uma instrução diferente: virar à esquerda, virar à direita, seguir em frente e executar uma função, cada um com uma cor e formato específico além do que, cada bloco possui internamente um resistor diferente, para que o Arduino UNO possa reconhecer o tipo do bloco inserido e possa enviar os comandos corretamente ao veículo. Assim em cada peça pode se ver externamente dois imãs similares ao da interface de controle que são soldados aos contatos do resistor, de forma a criar atração entre a peça e o encaixe e possibilitar o contato. O objetivo dos blocos é encaixá-los à plataforma de tal forma que as instruções criem a movimentação do veículo, na Figura 4 é visto a estrutura do bloco de codificação.

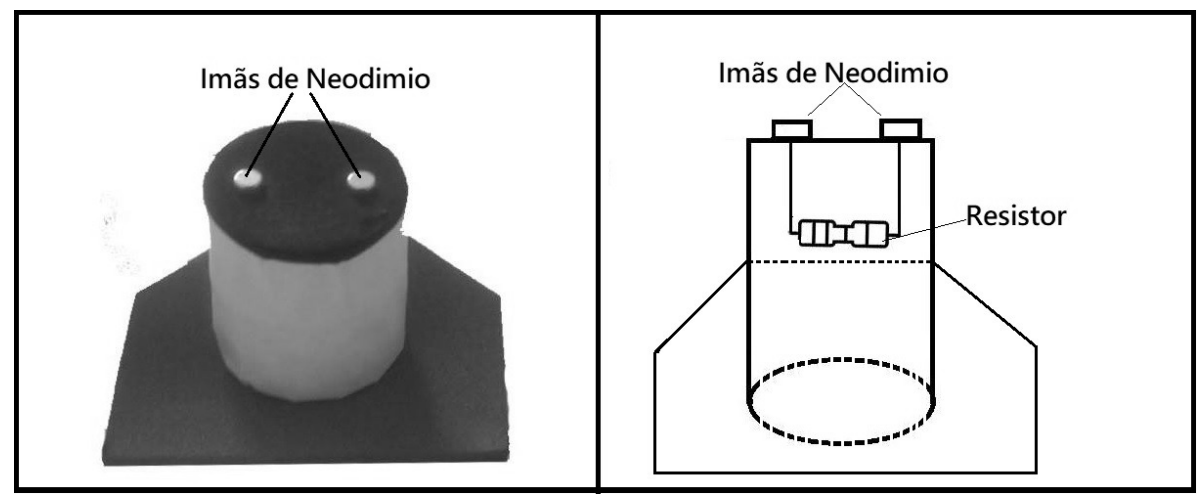

Figure 4. Estrutura do bloco de codificação

Para que a interface de controle possa interpretar os blocos de codificação foi utilizado o circuito da figura 5 junto com o microcontrolador Arduino UNO. Na figura, os 16 quadrados referem-se ao espaço do encaixe dos blocos de codificação. Na figura também podemos ver que cada encaixe tem sua própria trilha que é composta por duas linhas. A 
linha inferior é ligada ao GND do Arduino UNO e a superior aos 5 Volts do Arduino UNO, sendo que também existe um resistor de 10k ohms, que servirá para fazer um divisor de tensão com o resistor que se encontra no bloco de decodificação a ser encaixado, foram utilizados 4 valores diferentes de resistor de 220,4,7K, $10 \mathrm{~K}$ ou $100 \mathrm{~K}$ ohms usados para limitar a quantidade de corrente que vai passar no circuito para que o Arduino UNO possa reconhecer o tipo do bloco inserido e enviar os comandos corretamente ao veículo, os valores dos resistores foram baseados nos utilizados em [Kaviatkovski et al. 2016]. Esses diferentes valores de voltagem devem ser detetados nas entradas analógicas do microcontrolador.

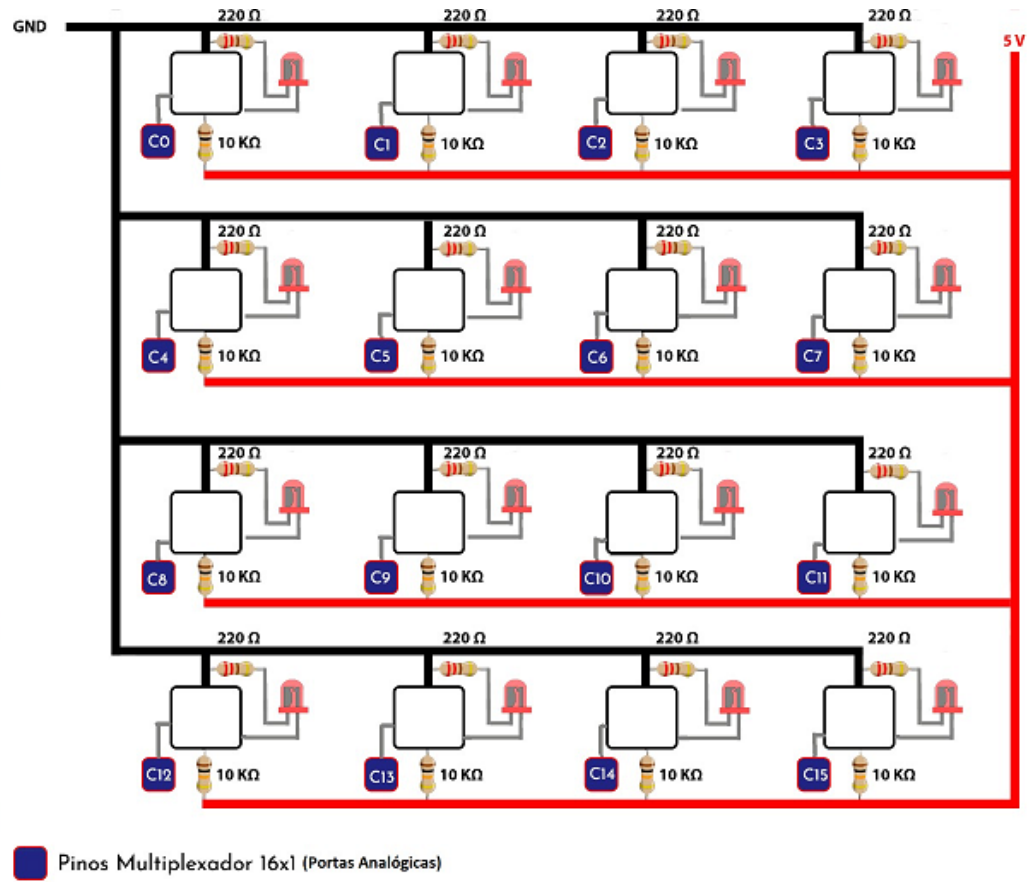

Figure 5. Esquema do circuito interno da interface de controle

Importante salientar que o Arduino UNO possui apenas 6 entradas analógicas, surgindo assim necessidade de um número de portas igual à quantidade necessária do projeto (16 portas), assim sendo, foi proposto o uso do multiplexador de 16:1 (74HC4067) que custa em média $\mathrm{R} \$ 16,00$, juntamente com o Arduino Uno, expandindo o número de portas no mesmo e obtendo assim a quantidade de portas analógicas necessárias para o desenvolvimento do protótipo, é possível também, a utilização de um Arduino Mega 2560, que já contém as 16 portas analógicas, com custo atual de $\mathrm{R} \$ 110,00$, nesse caso aumentaria o preço da proposta. Figura 6 mostra como foi feita a expansão, onde foram utilizadas 4 saídas digitais do Arduino UNO para selecionar uma das 16 sinais analógicas possíveis para ser enviada para o Arduino UNO, sendo assim na figura 5 os sinais iniciados em c vão para o MUX 16;1. Como observa-se na figura 5 ao encaixar um bloco de decodificação seu respetivo LED é acionado. Além disso na interface de controle também existe o botão acionador, sendo esse um botão switch comum que é ligado de forma que o botão fica em nível lógico baixo e, quanto pressionado, ele vai para nível lógico alto. 


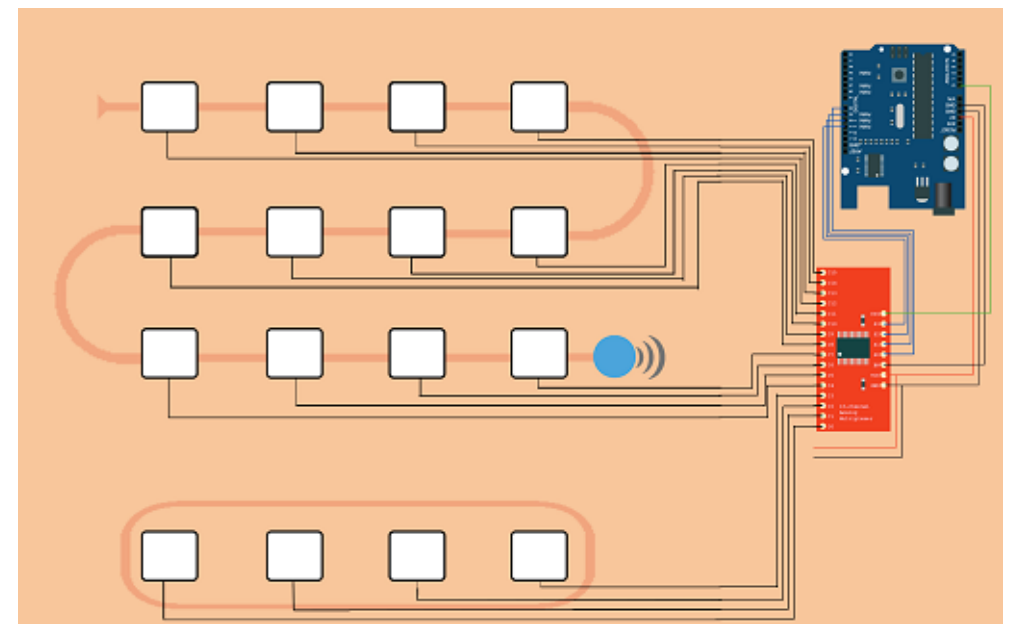

Figure 6. Expansão das linhas do Arduino UNO

Outro aspecto fundamental dessa interface é como ela realiza a conexão com o veículo. Quando o botão para executar os comandos é pressionado (botão start), a interface faz a leituras dos valores dos blocos encaixados e os envia sequencialmente para o veículo. Essa conexão é realizada através de módulos bluetooth HC-05 que oferece uma forma fácil e barata de comunicação. Após parear os módulos bluetooth, é criado um link serial via comunicação bluetooth entre ambos. O módulo bluetooth do veículo vai trabalhar em modo slave, enquanto na interface de controle, o módulo irá enviar comandos para o acionamento dos motores, fazendo o robô se mover para frente, direita ou esquerda.

\subsection{Tabuleiro educativo}

No brinquedo Cubetto um tabuleiro educativo é necessário para auxiliar os instrutores na realização de atividades com o intuito de apresentar os conceitos de lógica de programação. Nosso tabuleiro foi feito somente de borracha EVA que consistem num tablado de $1,25 \mathrm{~m} \times 1,25 \mathrm{~m}$ separado em quadrados de $25 \mathrm{~cm} \times 25 \mathrm{~cm}$ com ilustrações, como mostra a figura 7. Apesar dessas ilustrações darem um melhor aspecto estético ao tablado, elas são necessárias para a resolução dos desafios que se resumem a fazer o veículo se deslocar de um quadrado com ilustração até outro seguindo um conjunto de regras. Essas regras podem ser: fazer o deslocamento seguindo um caminho específico, usar uma quantidade limitada de blocos ou realizar manobras, não existe um limite definido uma vez que isso é determinado pela imaginação e criatividade dos usuários.

A seguir alguns exemplos ilustrativos: Posicionar o veículo no quadrado que contém a letra A, voltado para a direita, e pedir a criança para que ela desenvolva uma sequência com os blocos para que o carro se desloque até o quadrado com a letra E. Dessa forma ela deve ser capaz de informar que a sequência correta é formada por 4 blocos que movimenta o carro para frente. Os desafios também podem envolver a utilização de blocos distintos em quantidades diferentes. Por exemplo: análogo ao caso anterior, posicionar o carro no quadrado com a letra A porém, pedir para que a criança informe a sequência correta para deslocar o carro até o quadrado com o número 1. Logo a resposta para esse desafio é colocar 1 bloco de movimento para frente, 1 bloco para girar à direita e por fim mais 1 bloco de movimento para a frente.

Outros desafios considerados mais significativos são os que envolvem os blocos 


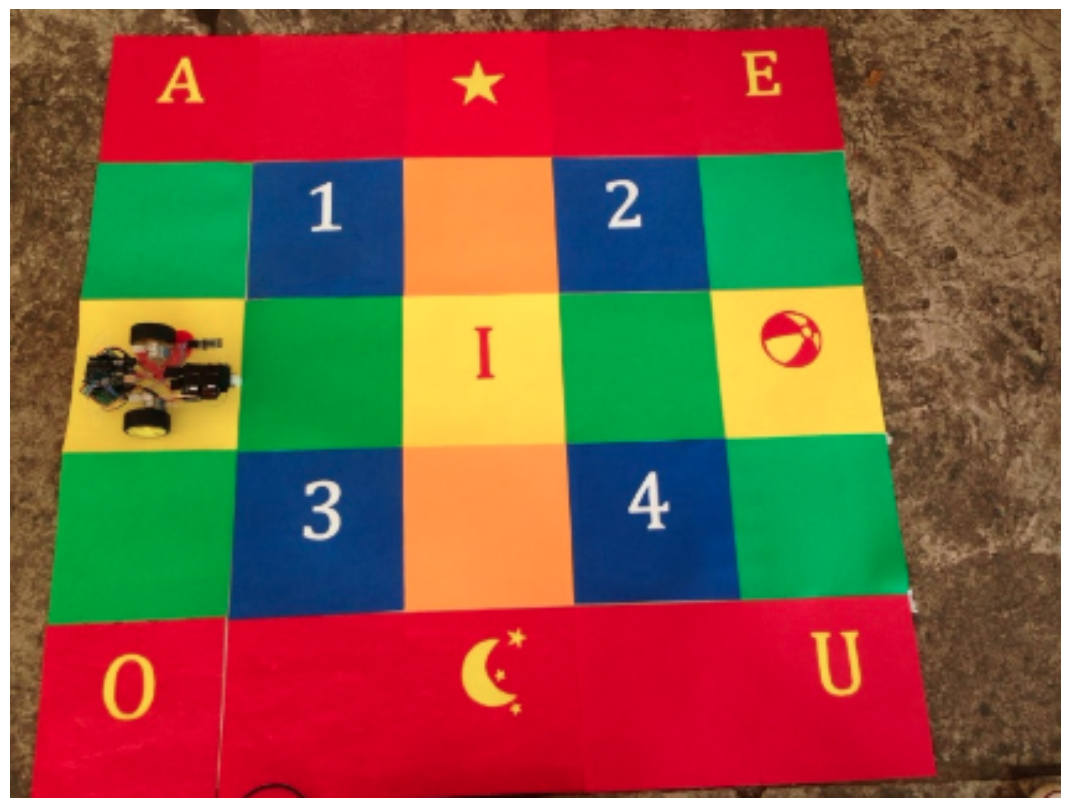

Figure 7. Carrinho com tabuleiro educativo utilizado para avaliação

de função, é sugerido que esse conceito seja apresentado depois que a criança estiver familiarizada com os demais blocos. Para explicar como esse bloco funciona pode-se usar a metáfora "Pacote", explicando que é possível representar uma sequência fixa de blocos de instrução apenas com 1 bloco de função. Entretanto isso pode ser uma tarefa complicada visto que o público alvo são crianças de 4 a 8 anos de idade, porém a forma aconselhada para mostrar isso segue os seguintes passos: Primeiro colocar dois blocos azuis (movimento para a frente) na sequencia principal da mesa de controle e pressionar o botão de execução. Isso irá mover o veículo para a frente por dois quadrados no tabuleiro. Logo após, colocar os dois blocos azuis na linha de função (última linha da mesa de controle) e colocar um bloco verde (bloco de função) na sequência principal e executar. Com isso, o veículo irá realizar o mesmo movimento. O objetivo é fazer as crianças observarem que o veículo pode executar a mesma ação de duas maneira diferentes. Evoluindo o conceito pode ser elaborada outra atividade no qual seja obrigatório usar o bloco de função para executar uma determinada tarefa como por exemplo se o exercício fosse realizar a trajetória de um quadrado de dois passos de lado utilizando o "pacote" anterior.

Outra atividade seria encaixar 4 blocos de virar a direita na parte de função e inserir na fila principal o bloco de função, ao executar, o veículo vai fazer uma volta completa de 360 graus. A atividade seria fazer um programa para que o veículo rode no seu próprio eixo avance duas vezes para frente e novamente gire no seu próprio eixo, usando o bloco de função anterior. Pode-se aproveitar para implementar este exercício também sem função.

Com desafios semelhantes aos apresentados, as crianças acabam aprendendo lógica de programação de forma intuitiva, pois são instruídas a pensar de forma estruturada quando criam as sequências de blocos. Dessa forma, a criança desenvolve o raciocínio lógico, analítico e crítico. Outro benefício esperado é a melhora na capacidade da criança solucionar problemas, em razão de que se, por acaso, uma sequência de blocos não for desenvolvida corretamente, o veículo não responderá de acordo e fará um 
trajeto errado no tabuleiro, então a criança se depara com uma situação que precisará ser resolvida, a fim de cumprir o desafio proposto.

\section{Resultados}

Foi verificado o correto funcionamento do protótipo ao executar diferentes desafios no tabuleiro. Também, o protótipo foi apresentado numa feira de profissões, e nela, voluntários testaram algumas funcionalidades do protótipo. Embora a maioria dos usuários não foram crianças, sentiram-se motivados a interagir com a ferramenta e entenderam a dinâmica do funcionamento.

Com base nos testes realizados percebeu-se que o robô poderia ter movimentos mais precisos, pois as vezes desvia da rota quando anda à frente, outra observação é que a bateria do robô poderia ter uma vida útil maior, como uma bateria de Litio de $500 \mathrm{~mA}$ ou uma bateria $9 \mathrm{~V}$ recarregável. A tabela 1 mostra o custo total de nossa proposta. O nosso protótipo é $70 \%$ mais barato que o kit Buddy Berry e $78 \%$ mais barato que o original.

Table 1. Tabela média de preços em reais atualizados para 2020

\begin{tabular}{|l|c|c|c|}
\hline Descrição do item & Quantidade & Valor unitário & Valor total \\
\hline Placa Arduino UNO & 2 & 30,00 & 60,00 \\
\hline Módulo Bluetooth serial HC-05 & 2 & 26,00 & 52,00 \\
\hline Kit chassi 2WD robô para Arduino & 1 & 62,00 & 62,00 \\
\hline Multiplexador 16:1 74HC4067 & 1 & 16,00 & 16,00 \\
\hline $\begin{array}{l}\text { Motor de passo modelo 27BYJ-48 e } \\
\text { driver Uln2003 }\end{array}$ & 2 & 19,00 & 38,00 \\
\hline Imãs de Neodímio (100 peças) & 1 & 90,00 & 90,00 \\
\hline Interface de madeira & 1 & 30,00 & 30,00 \\
\hline Tabuleiro educativo & 1 & 10,00 & 10,00 \\
\hline Outros materiais & - & - & 50,00 \\
\hline \multicolumn{1}{|c|}{ TOTAL } & - & - & $\mathbf{4 0 8 , 0 0}$ \\
\hline
\end{tabular}

\section{Conclusão}

Foi implementado um protótipo de hardware do brinquedo Cubetto, foram elaborados experimentos para ensino de lógica de programação e foi verificado seu correto funcionamento. Pelo seu baixo custo, este protótipo representa uma alternativa de reprodução para explorar as potencialidades da ferramenta educacional. Além disso, a elaboração deste projeto permitiu introduzir conceitos fundamentais de robótica educacional aos desenvolvedores do mesmo. Cabe salientar que este trabalho mostra a possibilidade de tornar acessível um dispositivo tecnológico para que crianças, principalmente de escolas e creches publicas, tenham a oportunidade de aprender conceitos de lógica de programação.

\section{Trabalhos Futuros}

Elaboração de estudo de caso com crianças para validação dos conceitos de uso de função do protótipo construído, assim como elaboração de outras interfaces para controle do robô, como através de aplicativo para celular, visando uma redução ainda maior no custo desse modelo de plataforma, já que a interface de controle passa a ser um aparelho celular. Em trabalhos futuros pode também ser considerado o uso do Raspberry Pi como alternativa ao Arduino Uno com o intuito de aumentar as funcionalidades do sistema. 


\section{Agradecimentos}

Os autores agradecem FAPESB pelo apoio em bolsa de iniciação cientifica e NBCGIB da UESC pela infraestrutura.

\section{Referências}

Abelson, Hal; Goodman, N. R. L. (1974). Logo language. https : / dspace.mit. edu/handle/1721.1/6226. Acessado em: 12-05-2019.

Azevedo, S., Aglaé, A., and Pitta, R. (2010). Minicurso: Introduçao a robótica educacional. 62a Reunião Anual da SBPC. Disponível em:; http://www. sbpcnet. org. br/livro/62ra/minicursos/MC\% 20Samuel\% 20Azevedo. pdf.

BATISTA, J. C. Robotoy: Ferramenta para ensino de programação para crianças usando robôs arduino.

Benitti, F. B. V., Vahldick, A., Urban, D. L., Krueger, M. L., and Halma, A. (2009). Experimentação com Robótica Educativa no Ensino Médio: ambiente, atividades e resultados. In Anais do Workshop de Informática na Escola, volume 1, pages 18111820 .

Cambruzzi, E. e Sousa, R. (2014). O Uso da Robótica Educacional para o Ensino de Algoritmos. Anais do EATI -Encontro Anual de Tecnologia da Informaçãoe Semana Acadêmica de Tecnologia da Informação, 4(1):40-47.

Cubetto (2013). Cubetto primo toys. https://www.primotoys.com/. Acessado em: 12-05-2019.

da Silva, P. F. and da Cruz Fagundes, L. (2016). Jabuti Edu: iniciando a lógica da programação com crianças da faixa etária de 4 aos 5 anos.

de Souza, L. F. F., Reis, G. L., Junior, M. A. A., and Pereira, E. B. A robótica educacional como ferramenta de estimulo para aprendizagem de crianças por meio da linguagem de programação logo: Um estudo de caso para a extensão.

dos Santos, T. N., Pozzebon, E., and Frigo, L. B. (2013). Utilização de Robótica nas Disciplicas da Educação Básica. Revista Técnico Científica do IFSC, 1(5):616.

Fernandes, C. d. C. (2013). S-educ: Um simulador de ambiente de robótica educacional em plataforma virtual. Master's thesis, Universidade Federal do Rio Grande do Norte.

Kaviatkovski, A. A., de Freitas, D. A., and Guedes, J. T. (2016). Buddy Berry: kit educativo com robô móvel para o ensino de lógica para crianças.

Pereira, G. Q. and Costa, V. G. (2010). Uso da Robótica Educacional no Ensino Fundamental: Um estudo de caso preliminar.

Rodarte, A. P. M. (2014). A robótica como auxílio à aprendizagem da matemática: percepções de uma professora do ensino fundamental público.

Torcato, P. (2012). O Robô ajuda? Estudo do Impacto do uso de Robótica Educativa como Estratégia de Aprendizagem na disciplina de aplicações informáticas B. In Congresso Internacional de TIC e Educação. Instituto de Educação da Universidade de Lisboa, pages 2578-2583. 
Zilli, S. d. R. (2004). A robótica educacional no ensino fundamental: perspectivas e prática. Master's thesis, Universidade Federal de Santa Catarina. 